\title{
CHLORINA MUTANTS OF BARLEY (Hordeum vulgare L.)
}

\author{
by \\ D.J. SIMPSON, O. MACHOLD", G. HØYER-HANSEN \\ and \\ D. von WETTSTEIN \\ Department of Physiology, Carlsberg Laboratory, \\ Gamle Carlsberg Vej 10, DK-2500 Copenhagen Valby \\ and \\ "Zentralinstitut für Genetik und Kulturpflanzenforschung der Akademie der Wissenschaften der DDR, \\ 4325 Gatersleben, DDR \\ Keywords: Carotenoids, chlorophyll, chloroplasts, fluorescence emission, fluorescence \\ induction kinetics, HPLC, polypeptides, SDS-polyacrylamide gel electrophoresis
}

\begin{abstract}
We have examined 31 new chlorina mutants of barley using in vivo absorption spectroscopy, $77 \mathrm{~K}$ fluorescence emission spectroscopy, room temperature fluorescence induction kinetics, HPLC separation of pigments and SDS-PAGE. Based on these properties they can be placed into 4 groups. The first group consists of 10 mutants which are allelic to the chlorophyll $b$-less chlorina- $f 2$ and comprises five strongly and three slightly leaky mutants at this locus. The decrease in chlorophyll $b$ content was correlated with a corresponding decrease in the amount of chlorophyll $a / b$-proteins in the thylakoids. One mutant (chlorina 106) was found which had a very low chlorophyll $b$ content and a deficiency in $\mathrm{Ch}_{a / b}-\mathrm{P} 2$, but was not allelic to chlorina-f2. The second group of chlorina mutants has unusual fluorescence properties, with a high Fm/Fo ratio. Gaussian deconvolution of the $77 \mathrm{~K}$ fluorescence emission spectra revealed an increase in the amplitude of components emitting at 694 and $718 \mathrm{~nm}$. The possibility is discussed that these properties result from the absence of the PSI connecting antenna LHCI-680. The third group has a Fs/Fo ratio $<1$, and other properties consistent with a partial deficiency in the chlorophyll $a$-proteins of PSII reaction centres. The fourth group consists of chlorina mutants which are very similar to wild-type in the properties examined, differing mainly in having a lower chlorophyll content.
\end{abstract}

\section{INTRODUCTION}

One of the most extensively studied higher plant nuclear gene mutant is the chlorophyll $b$-less barley mutant chlorina- $f 2$, and its alleles 2800,2807 and $3613(12,19,26)$. This mutation has proved invaluable in determining the role of chlorophyll $b$ in photosynthetic membranes and the function of the chlorophyll $a / b$-proteins. In the absence of chlorophyll $b$, none of the chlorophyll $b$-binding proteins are accumulated in the

\footnotetext{
Abbreviations: $\mathrm{CF}_{1}=$ extrinsic part of chloroplast coupling factor; $\mathrm{Chl}=$ chlorophyll; $\mathrm{DCMU}=3$-(3,4-dichlorophenyl)-1, 1-dimethylurea; Fm = maximum level of fluorescence; Fo = initial level of fluorescence; Fs = steady state level of fluorescence; Hepes = N-(hydroxyethyl)-piperazine-N'-ethane sulphonic acid; HPLC $=$ high performance liquid chromatography; $\mathbf{L H C}=$ light-harvesting complex; $\mathbf{P}=$ protein; $\mathrm{PS}=$ photosystem; tricine = $\mathrm{N}$-(tris-(hydroxymethyl)-methyl)glycine; SDS-PAGE = sodium dodecyl sulphate polyacrylamide gel electrophoresis; $\mathbf{W T}=$ wild-type.
} 
membrane $(13,15)$. Because the mutant is viable, it follows that the missing chlorophyll $a / b$-proteins are notessential for photosynthesis, but have a light-harvesting role. Conversely, only the three chlorophyll $a$-proteins in chlorina- $f 2$ thylakoids are possible candidates for the reaction centres of photosystem I and II (13).

Thylakoids from these mutants have also been used to assign specific spectral bands to chlorophyll $b$ or chlorophyll $a / b$-proteins in low temperature fluorescence emission spectra (15, 18) and circular dichroism spectra (6). The mutants have served as a source of thylakoids lacking the major chlorophyll $a / b$-protein $\left(\mathrm{Chl}_{a / b}-\mathrm{P} 2\right.$ or CPII), in studying the role of LHCII with respect to energy transfer, fluorescence induction, grana stacking and other cation-mediated phenomena $(3,21,26)$, and the location of LCHII within the membrane by freeze-fracture electron microscopy (22).

The precise nature of the lesion in chlorina- $f 2$ has not been discovered. It has been shown that the genes for $\mathrm{Chl}_{a / b}-\mathrm{P} 2$ are transcribed (1). The m-RNA is translated, and the polypeptides transported into the chloroplasts, processed and inserted into the thylakoid, where they are rapidly destroyed $(20)$. It is suspected that the mutation affects the enzyme which converts chlorophyll $a$ to chlorophyll $b$, and in the absence of chlorophyll $b$, the chlorophyll $a / b$ -

Table I.

Data on chlorina mutants in barley

\begin{tabular}{|c|c|c|c|c|}
\hline Mutants & Year of isolation & Variety & Mutagen & Special remarks \\
\hline \multicolumn{5}{|l|}{ chlorina- $f 2^{12}$} \\
\hline chlorina- $f 2^{2800}$ & & Donaria & & \\
\hline chlorina- $f 2^{2807}$ & & Donaria & & \\
\hline chlorina- $f 2^{3613}$ & & Donaria & & \\
\hline chlorina- $f 2^{101}$ & 1980 & Tron & $\mathrm{NaN}_{3}$ & \\
\hline chlorina-f $2^{102}$ & 1980 & Tron & $\mathrm{NaN}_{3}$ & \\
\hline chlorina- $f 2^{103}$ & 1980 & Tron & $\mathrm{NaN}_{3}$ & \\
\hline chlorina- ${ }^{104}$ & 1980 & Tron & $\mathrm{NaN}_{3}$ & not allelic with $f c, f 8$ \\
\hline chlorina- $f 2^{105}$ & 1980 & Tron & $\mathrm{NaN}_{3}$ & \\
\hline cchlorina- ${ }^{106}$ & 1980 & Tron & $\mathrm{NaN}_{3}$ & not allelic with $f_{\mathcal{C}} f 7, f 8$ \\
\hline chlorina- $f 2^{107}$ & 1980 & Tron & $\mathrm{NaN}_{3}$ & \\
\hline chlorina- $f 2^{108}$ & 1980 & Tron & $\mathrm{NaN}_{3}$ & \\
\hline chlorina- $f 2^{109}$ & 1980 & Tron & $\mathrm{NaN}_{3}$ & \\
\hline chlorina- $f c^{110}$ & 1981 & Bonus & $\mathrm{NaN}_{3}$ & \\
\hline chlorina- ${ }^{111}$ to $-^{117}$ & 1981 & Bonus & $\mathrm{NaN}_{3}$ & not allelic with $f c_{2} f 7, f 8$ \\
\hline chlorina- ${ }^{118}$ & 1981 & Bonus & $\mathrm{NaN}_{3}$ & \\
\hline chlorina- ${ }^{119}$ & 1981 & Bonus & $\mathrm{NaN}_{3}$ & not allelic with $f c_{2} f 7, f 8$ \\
\hline chlorina- ${ }^{120}$ & 1981 & Bonus & $\mathrm{NaN}_{3}$ & not allelic with $f 7, f 8$ \\
\hline chlorina- ${ }^{121}$ & 1981 & Bonus & $\mathrm{NaN}_{3}$ & not allelic with $f c, f 7 f \mathcal{B}$ \\
\hline chlorina- $f 2^{122}$ & 1981 & Bonus & $\mathrm{NaN}_{3}$ & \\
\hline chlorina- $f 2^{123}$ & 1981 & Bonus & $\mathrm{NaN}_{3}$ & \\
\hline chlorina- ${ }^{124}$ & 1981 & Bonus & $\mathrm{NaN}_{3}$ & not allelic with $f c_{2} f 7, f 8$ \\
\hline chlorina- $^{125}$ & 1981 & Bonus & $\mathrm{NaN}_{3}$ & \\
\hline chlorina- ${ }^{126}$ & 1981 & Bonus & $\mathrm{NaN}_{3}$ & not allelic with $f c_{2} f 7, f 8$ \\
\hline chlorina- ${ }^{127}$ & 1981 & Bonus & $\mathrm{NaN}_{3}$ & \\
\hline chlorina- ${ }^{129}$ & 1981 & Bonus & $\mathrm{NaN}_{3}$ & \\
\hline chlorina- ${ }^{130}$ & 1981 & Bonus & $\mathrm{NaN}_{3}$ & not allelic with $f 7, f 8$ \\
\hline chlorina- ${ }^{132}$ & 1981 & Bonus & $\mathrm{NaN}_{3}$ & not allelic with $f 8$ \\
\hline chlorina- $f 2^{133}$ & 1981 & Bonus & $\mathrm{NaN}_{3}$ & \\
\hline chlorina- ${ }^{134}$ & 1981 & Bonus & $\mathrm{NaN}_{3}$ & not allelic with $f c, f 7 f 8$ \\
\hline chlorina- ${ }^{135}$ & 1981 & Bonus & $\mathrm{NaN}_{3}$ & not allelic with $f 7$ \\
\hline
\end{tabular}


proteins are unstable and are rapidly degraded by proteolysis. Apart from the major $\mathrm{Chl}_{a / b}-\mathrm{P} 2$ (CPII), there is a minor component $\mathrm{Chl}_{a / b}-\mathrm{Pl}$ (11) which may serve as an antenna for PSII, and there are the polypeptide complexes, LHCI-680 and LHCI-730 which serve as connecting antenna and light-harvesting antenna, respectively, for PSI (2). It is clear that chlorina- $f 2$ is not a mutation in one of the structural genes coding for a chlorophyll $a / b$-protein.

This paper describes the initial characterisation of 31 new chlorina mutants in barley. They were selected with the aim of finding mutants in which individual chlorophyll $a / b$ proteins are genetically removed, so that their function and the control of their biosynthesis could be studied.

\section{MATERIALS AND METHODS}

\subsection{Screening and genetic analysis}

Seeds of Hordeum vulgare L. cvs. Sejets Tron and Svalövs Bonus were mutagenised by azide treatment as described in (9) and sown in the field. The M2 seeds from these plants were germinated the following year and 4-week old seedlings were screened visually for light-green colour. Those which survived and produced viable seeds were subsequently propagated for further generations and numbered chlorina 101135. All mutants were crossed with chlorina$f 2^{2800}$ or chlorina- $f 2^{2}$. As shown in Tables I and II, ten of the chlorina mutants were allelic to these previously known chlorophyll $b$-less mutants. Since several of the new mutants were leaky with repect to chlorophyll $b$ synthesis, it is important to identify the different alleles at the chlorina- $f 2$ gene and these are listed in Table I. We suggest clo as the gene symbol for the chlorina mutants. Chlorina 110 is an allele of the gene $f c$. Since in our hands, $f c$ is sublethal, we used heterozygous plants for the crosses, which resulted in a $1: 1$ segregation (Table II). Besides the mutants in the $f 2$ gene, chlorina 106 proved to be deficient in chlorophyll $b$, but gave only wild-type progeny in crosses with $f 2$ (Table II). Many of the new mutants have been tested for allelism with the chlorina genes $f 7$ and $f 8$, as well as with each other, but the diallele is not yet complete.
Table II.

Results of crosses between chlorina mutants

\begin{tabular}{lr}
\hline Combination & $\begin{array}{l}\text { F1 progeny seedlings } \\
\text { wild type : chlorina }\end{array}$ \\
\hline clo- 2 & $0: 77$ \\
$2800 \times 101$ & $0: 54$ \\
$2800 \times 102$ & $0: 102$ \\
$2800 \times 103$ & $0: 39$ \\
$2800 \times 105$ & $0: 86$ \\
$2800 \times 107$ & $0: 81$ \\
$2800 \times 108$ & $0: 26$ \\
$f 2 \times 109$ & $0: 37$ \\
$2800 \times 122$ & $0: 36$ \\
$2800 \times 123$ & $0: 75$ \\
$2800 \times 133$ & $55: 0$ \\
$2800 \times 106$ & \\
$c l o-f c$ & $47: 44$ \\
$f c /+\times 110$ & \\
\hline
\end{tabular}

\subsection{Plant material}

Seeds of the chlorina mutants were germinated in tap water moistened vermiculite and harvested after 7 days at $22^{\circ} \mathrm{C}$ under continuous white light (1700 lux, Philips TL $40 \mathrm{~W}$ ) as previously described (13).

\subsection{Pigment determination}

Approximately $3 \mathrm{~g}$ of leaves were weighed, frozen in liquid nitrogen and ground with a mortar and pestle in the presence of $\mathrm{NaHCO}_{3}$. The resulting fine powder was extracted 4 times with $100 \%$ acetone, and the combined extracts used for HPLC analysis. The pigments were separated on a $\mathrm{C} 18$ reverse phase column with a linear gradient of $90 \%$ methanol to $100 \%$ ethyl acetate, as described in (7).

\subsection{In vivo spectroscopy}

An estimate of the chlorophyll $a / b$ ratio was also obtained by in vivo absorption spectroscopy using an Aminco DW 2a spectrophotometer. The absorbance of whole leaves at 650 and 678 $\mathrm{nm}$ was measured for wild-type and the chlorophyll $b$-less mutant 2800 . The chlorophyll $b / a$ ratio for the chlorina seedling leaves was calcu- 


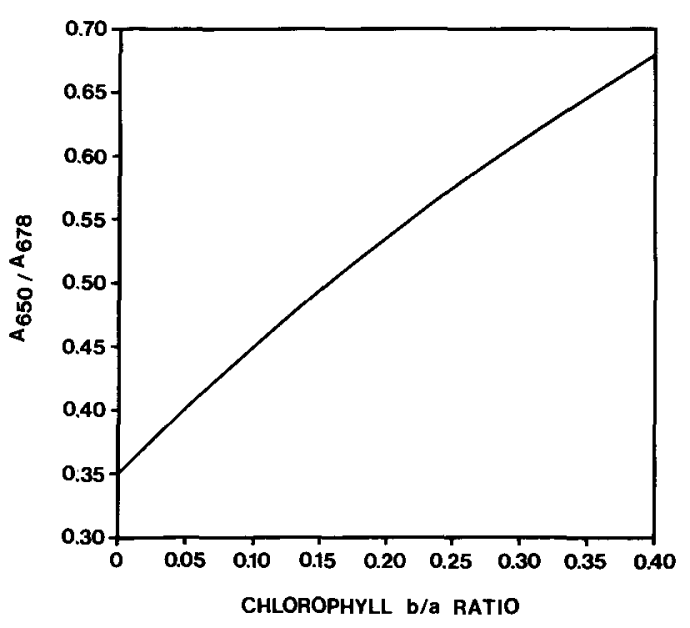

Figure 1. Plot of the chlorophyll $b / a$ ratio vs the ratio of in vivo absorption at 650 and $678 \mathrm{~nm}$ using the equation derived in section 2.4. Over the range 0 to 0.3 , corresponding to chlorophyll $a / b$ values of $\infty$ to 3.3 , the relationship was almost linear. This method gave a good estimate for all but the mutants in Table VI, for which the chlorophyll $a / b$ ratios were overestimated by a factor of 2 .

lated from their absorbance at 650 and $678 \mathrm{~nm}$ using the following formula:

$$
\text { b/a ratio }=\frac{f A 678-f A 650}{r\left[A 650\left(w^{\prime}-f^{\prime}\right)-A 678(w-f)\right]}
$$

where $\mathrm{A} 650=$ absorbance at $650 \mathrm{~nm}$ of sample

A678 = absorbance at $678 \mathrm{~nm}$ of sample

f $\quad=$ A650 of chlorophyll $b$-less mutant

f $\quad=$ A678 of chlorophyll $b$-less mutant

$\mathrm{w} \quad=\mathrm{A} 650$ of wild-type

$\mathrm{w}^{\prime} \quad=\mathrm{A} 678$ of wild-type

$\mathrm{r} \quad=$ chlorophyll $a / b$ ratio of wild-type

For $b / a$ ratios between 0 and 0.3 , this produces an almost linear relationship (Figure 1), which can be approximated by the equation:

$$
\text { b/a ratio }=\frac{r\left(w f^{\prime}-w^{\prime} f\right)}{w^{\prime} f^{\prime}} \times \frac{A 650}{A 678}+\frac{f}{f^{\circ}}
$$

Deviation from linearity is greater if the chlorophyll content of the chlorophyll $b$-less standard is much lower than the wild-type. Since this was not the case, this technique was found to be a rapid and usually reliable screening method for determining the chlorophyll $a / b$ ratios of large numbers of leaves.

\subsection{Fluorescence measurements}

Room temperature fluorescence induction kinetics of dark-adapted seedling leaves were measured using the blue excitation light, photodiode and digital oscilloscope apparatus previously described (25). A Compur electronic shutter enabled Fo to be measured $0.6 \mathrm{msec}$ after illumination. To obtain a comparative estimate of the size of PSII units, excised leaves were incubated in $10 \mu \mathrm{M}$-DCMU with $25 \mathrm{ppm}$ Triton $\mathrm{X}-100$ as a wetting agent. The fluorescence induction kinetics were recorded and the time at which the variable fluorescence $(\mathrm{Fv})$ had reached half its maximum value $\left(t_{1 / 2}\right)$ was read directly from the oscilloscope. Low temperature fluorescence emission spectra were recorded from whole leaves at $77 \mathrm{~K}$ using the apparatus described in (25), with a baseline subtraction providing some correction for the light source and photomultiplier response. The excitation light in all cases (quartz halogen light passing through two Corning 2-96 broad band blue filters) was $400 \mu \mathrm{E} \cdot \mathrm{m}^{-2} \cdot \mathrm{s}^{-1},(400-700 \mathrm{~nm})$, measured with a LI-COR photometer model LI$185 \mathrm{~B}$ with quantum sensor.

Spectral deconvolution into component Gaussian curves was performed with the programme RESOL, translated into BASIC and run on a Hewlett-Packard 9836 S computer.

\subsection{Polyacrylamide gel electrophoresis}

Seedling leaves were homogenised in a razor blade blender with 2 volumes of cold $0.4 \mathrm{M}$-sucrose, $50 \mathrm{mM}$-tricine, $\mathrm{pH} 7.8$ and $10 \mathrm{mM}-\mathrm{MgCl}_{2}$. Thylakoids were isolated by differential centrifugation for $5 \mathrm{~min}$ at $1400 \times \mathrm{g}$ and washed in 25 mM-Hepes, $10 \mathrm{mM}$-EDTA before solubilising in SDS (13). Polypeptides were separated by ureaSDS-polyacrylamide gel electrophoresis (12$18 \%$ acrylamide gradient) using system III (13). Gels were fixed and then stained with Coomassie Blue R-250. 
Table III.

Pigment analysis of chlorina mutants by HPLC

\begin{tabular}{|c|c|c|c|c|c|c|}
\hline \multirow[b]{2}{*}{ Mutant } & \multicolumn{6}{|c|}{ Pigment (molecules of pigment/1000 molecules of chlorophyll) } \\
\hline & Neoxanthin & Violaxanthin & Lutein & $\beta$-carotene & chlorophyll $a$ & chlorophyll $b$ \\
\hline wild-type & 45 & 44 & 138 & 76 & 771 & 229 \\
\hline chlorina- $f 2$ & 25 & 93 & 173 & 107 & 998 & 2 \\
\hline 101 & 21 & 51 & 128 & 112 & 996 & 4 \\
\hline 102 & 27 & 66 & 162 & 137 & 987 & 13 \\
\hline 103 & 27 & 78 & 167 & 109 & 980 & 20 \\
\hline 105 & 10 & 42 & 168 & 121 & 983 & 17 \\
\hline 107 & 39 & 53 & 134 & 95 & 856 & 144 \\
\hline 108 & 12 & 59 & 141 & 116 & 1000 & 0 \\
\hline 109 & 50 & 80 & 163 & 98 & 873 & 127 \\
\hline 122 & 42 & 33 & 106 & 86 & 857 & 143 \\
\hline 123 & 38 & 40 & 125 & 112 & 893 & 107 \\
\hline 106 & 79 & 149 & 228 & 55 & 899 & 101 \\
\hline 104 & 34 & 43 & 113 & 117 & 817 & 183 \\
\hline 111 & 34 & 32 & 115 & 64 & 794 & 206 \\
\hline 117 & 26 & 40 & 111 & 124 & 805 & 195 \\
\hline 119 & 26 & 25 & 105 & 99 & 814 & 186 \\
\hline 125 & 51 & 34 & 113 & 84 & 787 & 213 \\
\hline 126 & 40 & 72 & 153 & 126 & 807 & 193 \\
\hline 113 & 47 & 49 & 140 & 48 & 746 & 254 \\
\hline 114 & 53 & 42 & 152 & 61 & 771 & 229 \\
\hline 115 & 49 & 39 & 125 & 38 & 755 & 245 \\
\hline 121 & 39 & 27 & 122 & 71 & 787 & 213 \\
\hline 124 & 43 & 33 & 120 & 46 & 754 & 246 \\
\hline 110 & 38 & 37 & 118 & 34 & 769 & 231 \\
\hline 112 & 52 & 49 & 141 & 58 & 750 & 250 \\
\hline 116 & 84 & 53 & 60 & 90 & 786 & 214 \\
\hline 118 & 70 & 40 & 116 & 88 & 790 & 210 \\
\hline 132 & 42 & 29 & 123 & 73 & 762 & 238 \\
\hline
\end{tabular}

\section{RESULTS}

Genetic analysis of the chlorina mutants (see section 2.1 ) revealed that 10 were allelic to the chlorophyll $b$-less chlorina- $2^{\mathfrak{f}}$. In vivo absorption spectroscopy indicated that 5 had very low or no chlorophyll $b$. Pigment analysis by HPLC showed that only chlorina 101 and 108 were actually free of chlorophyll $b$, while chlorina 102,103 and 105 contained between $6-9 \%$ of wild-type (Table III). Chlorina 107, 109, 122, 123 and 133 were more leaky, with chlorophyll $a / b$ ratios between 6 and 8 , corresponding to a chlorophyll $b$ level about half wild-type.
Those mutants with chlorophyll $a / b$ ratios $>$ 10 had $77 \mathrm{~K}$ fluorecence emission spectra characterised by small shoulders around 685 and 695 $\mathrm{nm}$ and a broad peak with a maximum between 735 and $738 \mathrm{~nm}$. Computer deconvolution of these spectra into component Gaussian curves produced very similar results, with consistent values for peak maxima, halfwidth and amplitude (Figure 2B, Table IV). Compared with wild-type, which could be best fitted with 7 Gaussians at 680, 685, 694, 715, 742, 761 and $770 \mathrm{~nm}$ (Figure 2A), these chlorina mutants lacked the $680 \mathrm{~nm}$ component, and had reduced 
Table IV.

Gaussian deconvolution of $77 \mathrm{~K}$ fluorescence emission spectra

\begin{tabular}{|c|c|c|c|c|c|c|c|}
\hline \multicolumn{8}{|c|}{ Wild-type $\sigma=1.345^{*}$} \\
\hline wavelength (nm) & 680.4 & 685.3 & 693.6 & 714.6 & 742.1 & 760.7 & 770.3 \\
\hline halfwidth (nm) & 7.6 & 6.9 & 20.2 & 18.7 & 24.9 & 20.2 & 36.7 \\
\hline amplitude & 35.6 & 135.9 & 263.4 & 107.8 & 963.7 & 130.5 & 114.5 \\
\hline percent of area & 0.7 & 2.4 & 13.5 & 5.1 & 60.9 & 6.7 & 10.7 \\
\hline \multicolumn{8}{|c|}{ chlorina $101 \sigma=1.917$} \\
\hline wavelength (nm) & & 685.3 & 698.5 & 719.9 & 737.5 & 762.0 & 775.3 \\
\hline halfwidth $\quad(\mathrm{nm})$ & & 5.9 & 24.4 & 19.1 & 30.7 & 20.9 & 36.4 \\
\hline amplitude & & 24.4 & 136.1 & 186.6 & 972.7 & 63.0 & 93.7 \\
\hline percent of area & & .3 & 8.0 & 8.5 & 71.8 & 3.2 & 8.2 \\
\hline \multicolumn{8}{|c|}{ chlorina 101 (in glasshouse) $\sigma=1.994$} \\
\hline wavelength (nm) & & 685.7 & 697.9 & 721.5 & 737.6 & 762.0 & 775.1 \\
\hline halfwidth (nm) & & 6.1 & 22.9 & 22.9 & 30.8 & 23.3 & 34.8 \\
\hline amplitude & & 44.7 & 255.7 & 496.1 & 780.1 & 69.5 & 79.2 \\
\hline percent of area & & .6 & 12.7 & 24.7 & 52.4 & 3.5 & 6.0 \\
\hline \multicolumn{8}{|c|}{ chlorina $107 \sigma=1.528$} \\
\hline wavelength $(\mathrm{nm})$ & & 685.4 & 696.6 & 718.3 & 742.9 & 761.4 & 770.3 \\
\hline halfwidth $(\mathrm{nm})$ & & 6.8 & 24.0 & 18.7 & 24.4 & 18.3 & 30.2 \\
\hline amplitude $\quad 47.2$ & & 156.9 & 109.2 & 976.6 & 147.8 & 159.4 & \\
\hline percent of area & & .9 & 10.0 & 5.4 & 63.6 & 7.2 & 12.8 \\
\hline \multicolumn{8}{|c|}{ chlorina $126 \sigma=2.623$} \\
\hline wavelength (nm) & & 685.1 & 693.1 & 718.0 & 739.6 & 761.8 & 775.2 \\
\hline halfwidth $\quad(\mathrm{nm})$ & & 6.9 & 19.8 & 22.2 & 28.8 & 19.9 & 36.2 \\
\hline amplitude & & 218.5 & 512.9 & 493.6 & 948.2 & 90.3 & 110.0 \\
\hline percent of area & & 2.7 & 18.2 & 19.7 & 49.1 & 3.2 & 7.1 \\
\hline
\end{tabular}

${ }^{*} \sigma$ indicates the goodness of fit. The lower the value, the better the fit.

amplitudes of bands at 685 and 699 , whereas the band at $720 \mathrm{~nm}$ had increased amplitude. The major peak occurred at 737 instead of $742 \mathrm{~nm}$. In contrast, the leaky mutants chlorina 107,109 , 122,123 and 133 had components at 685 and $697 \mathrm{~nm}$ with amplitudes about half that of wild-type, and the peaks at 715 and $742 \mathrm{~nm}$ were similar in amplitude to those found in wild-type (Figure 2C, Table IV).

The differences in the long wavelength peak value of the mutants in the chlorina- $f 2$ gene (Table V) could readily be explained in terms of the relative amplitudes of the components at 720 and $737 \mathrm{~nm}$. When chlorina 101, 102, 103, 105 and 108 were grown in a glasshouse, with a daily maximum of $17{ }^{\circ} \mathrm{C}$ in spring, the peak fluorescence maxima shifted to as low as $726 \mathrm{~nm}$, due to a 2-3 fold increase in the amplitude of the 720 $\mathrm{nm}$ component (Figure 2D). The amplitude of the $697 \mathrm{~nm}$ component also increased under these growth conditions. In contrast, the leaky mutants did not have altered $77 \mathrm{~K}$ fluorescence emission spectra under these conditions.

The photosynthetic unit size of PSII was estimated by the half-rise time $\left(t_{1 / 2}\right)$ of the variable fluorescence in the presence of DCMU, using 

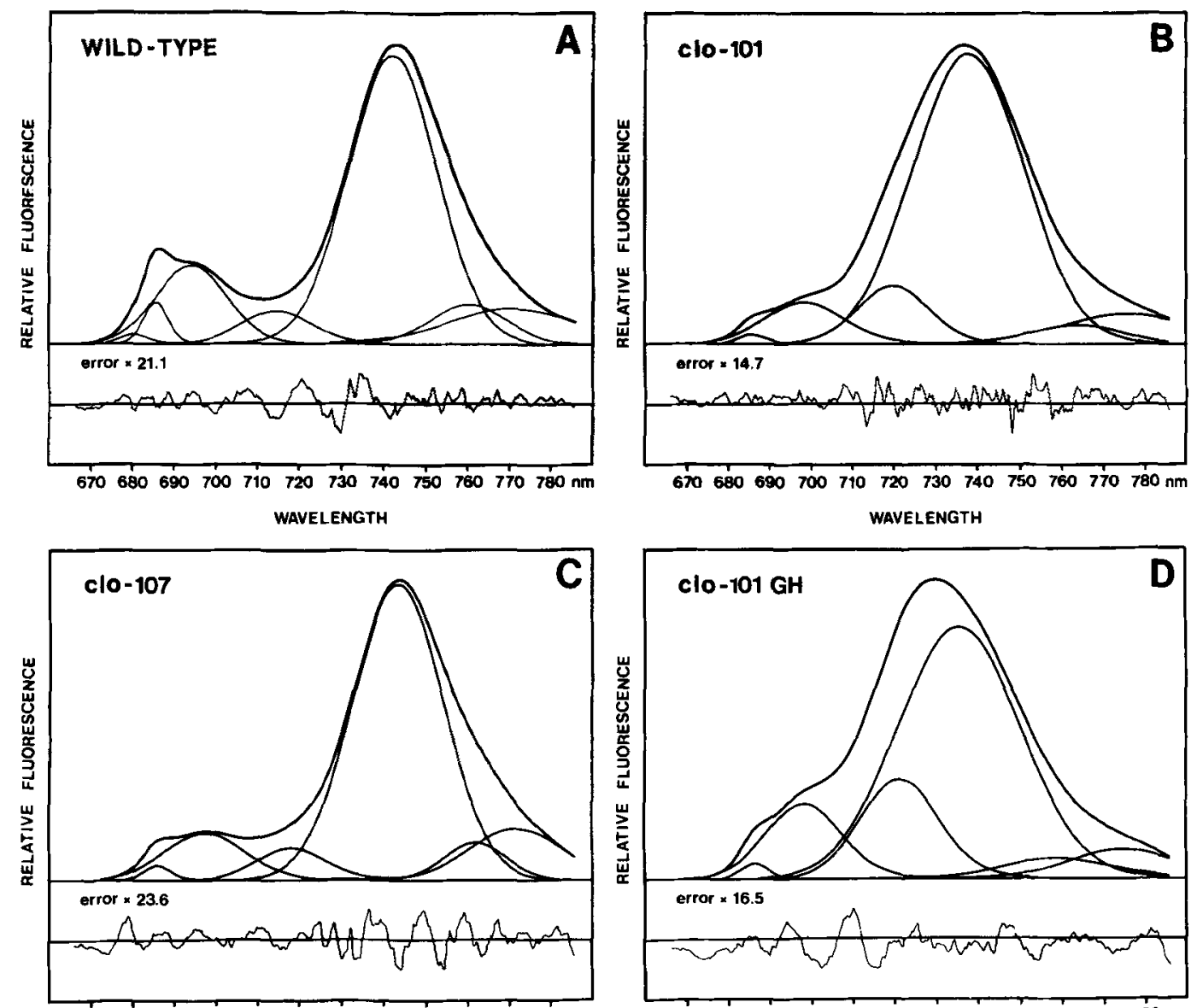

$670 \quad 680 \quad 690700710 \quad 720730740 \quad 750 \quad 760 \quad 770 \quad 780 \mathrm{~nm}$ WAVELENGTH

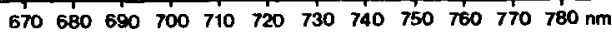
WAVELENGTH

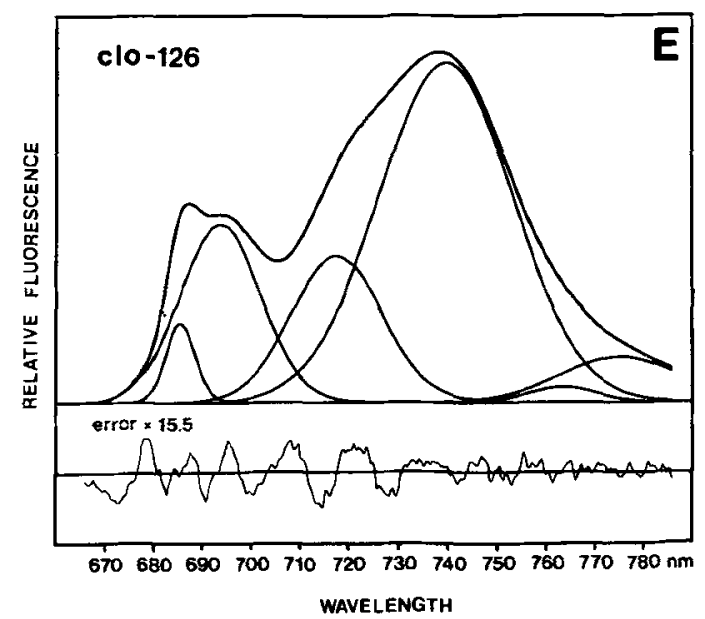

Figure 2A-E. Fluorescence emission spectra at $77 \mathrm{~K}$ taken from whole leaves and analysed by Gaussian deconvolution using the programme RESOL. The upper curve is the sum of the component curves, the parameters for which are given in Table IV. The error curve represents the difference between the data points of the spectrum and the upper curve, on a scale indicated by the designated magnification. (clo = chlorina; $\mathrm{GH}=$ glasshouse) 
Table V.

Chlorina mutants allelic to chlorina- $f 2$

\begin{tabular}{llllllll}
\hline Mutant & $\begin{array}{l}\text { chlorophyll } \\
\text { (\% of WT) }\end{array}$ & $\begin{array}{l}\text { chlorophyll } \\
a / b \text { ratio }\end{array}$ & $\mathbf{t}_{1 / 2}$ & Fm/Fo & Fs/Fo & $\begin{array}{l}77 \text { K fluores- } \\
\text { cence peak (nm) }\end{array}$ & $\begin{array}{l}\text { F685/F742 } \\
\text { ratio }\end{array}$ \\
\hline 101 & 60 & 239 & 9.31 & 4.167 & 1.612 & 735 & 0.080 \\
102 & 46 & 77 & 7.79 & 4.220 & 1.907 & 738 & 0.074 \\
103 & 95 & 49 & 8.41 & 4.316 & 2.204 & 738 & 0.067 \\
105 & 60 & 59 & 7.90 & 3.663 & 1.925 & 736 & 0.078 \\
107 & 49 & 6.0 & 4.11 & 6.240 & 2.605 & 742 & 0.130 \\
108 & 74 & $\infty$ & 7.42 & 3.897 & 1.903 & 735 & 0.080 \\
109 & 86 & 6.9 & 2.40 & 5.471 & 2.517 & 742 & 0.093 \\
122 & 73 & 6.0 & 5.54 & 4.503 & 2.443 & 741 & 0.165 \\
123 & 71 & 8.3 & 5.29 & 4.975 & 3.159 & 742 & 0.136 \\
133 & 65 & 5.7 & 4.68 & 4.496 & 1.373 & 740 & 0.165 \\
chlorina-f2 & 81 & 409 & - & 3.421 & 2.708 & 735 & 0.315 \\
wild-type & $100^{*}$ & 3.4 & 2.16 & 5.898 & 3.064 & 742 & 0.090 \\
\hline 106 & 42 & 8.9 & 8.03 & 2.487 & 1.389 & 737 & \\
\hline
\end{tabular}

intact leaves. Mutants with chlorophyll $a / b>$ 10 had $t_{1 / 2}$ values about 4 times higher than wild-type, whereas those with chlorophyll $a / b<$ 10 generally had $t_{1 / 2}$ values about twice that of wild-type (Table V). Since this parameter is inversely proportional to the photosynthetic unit size, this means that there was a decrease in antenna size corresponding to the decrease in chlorophyll $b$ content. This in turn was related to a decrease in the intensity of the Coomassie staining polypeptide bands of $\mathrm{Chl}_{a / b}-\mathrm{P} 2$, which is the major light-harvesting chlorophyll-protein of PSII (Figure 3). The amount of these polypeptides was proportional to the level of chlorophyll $b$ in the mutant. Thus chlorina 101 and 108 had no bands, while faint bands were seen in chlorina 102,103 and 105 and moderately heavy bands in the others. There was also a proportionate decrease in the intensity of polypeptides in the 20-25 kD region, indicated by arrows in Figure 3.

Only one mutant was found which had a high chlorophyll $a / b$ ratio that was not a mutation in the chlorina- 2 gene. Chlorina 106 had almost no $685 \mathrm{~nm}$ component, and the 695 Gaussian was at $701 \mathrm{~nm}$. It had a very small PSII antenna size $\left(t_{1 / 2}=8.03 \mathrm{sec}\right)$ and SDS-PAGE showed that $\mathrm{Chl}_{a / b}-\mathrm{P} 2$ was present, but in low levels. The pigment composition was unusual in having high levels of neoxanthin, violaxanthin and lutein relative to chlorophyll $a$ (Table III). This was quite different from the chlorina- $f 2$ mutants, which had a relatively high amount of $\beta$-carotene.

A second group of mutants could be distinguished on the basis of their $77 \mathrm{~K}$ fluorescence emission spectra, which showed a very broad long wavelength peak blue-shifted from $742 \mathrm{~nm}$ accompanied by higher than normal yields at 685 and $695 \mathrm{~nm}$ (Table VI). Deconvolution analysis demonstrated that this could be explained by a specific increase in the amplitude of the component at 718-719 nm (Figure 2E, Table IV), as also found for the chlorina- $f 2$ mutants. This peak was not sensitive to growth conditions for chlorina 117, 125, 126 and 134, whereas its amplitude was the same as wild-type under normal growth conditions for chlorina 104, 111 , 129 and 130 but increased in amplitude when grown in the glasshouse. The opposite was found for chlorina 119. The increase in fluorescence yield at short wavelengths was due to a doubling of the amplitude of the component at $694 \mathrm{~nm}$ (Table IV).

For the mutants in this group, the chlorophyll $a / b$ ratios determined from in vivo absorption 


\section{chlorina}

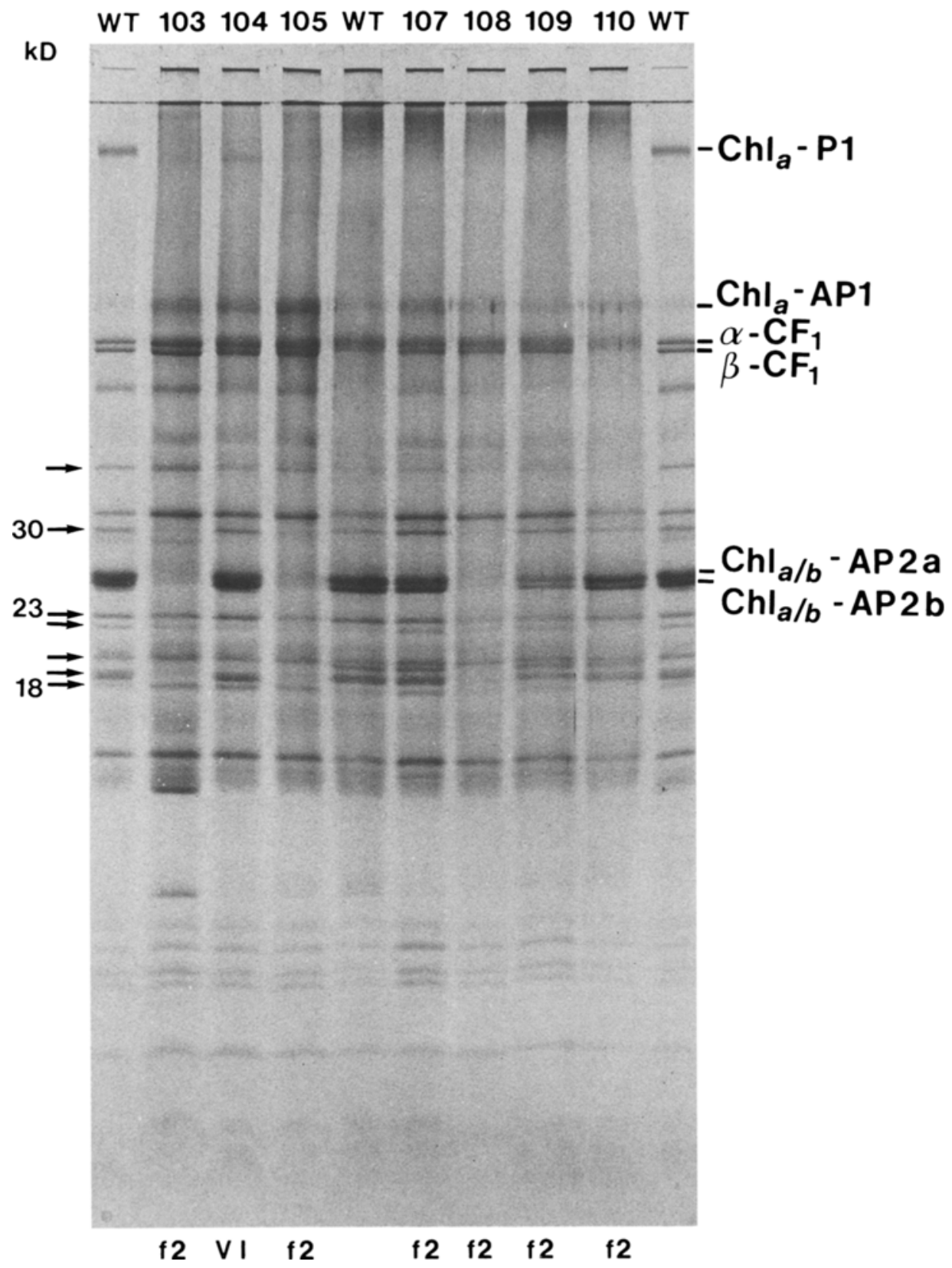

Figure 3. Polypeptide patterns of chlorina mutants. Thylakoid membrane polypeptides ( $2 \mu \mathrm{g}$ chlorophyll) from wild-type and mutants were separated on 12-18\% SDS-PAGE. Polypeptides affected are indicated with arrows if not identified by name. Each track is labelled with the mutant gene, or the table number in which the mutant is described. 


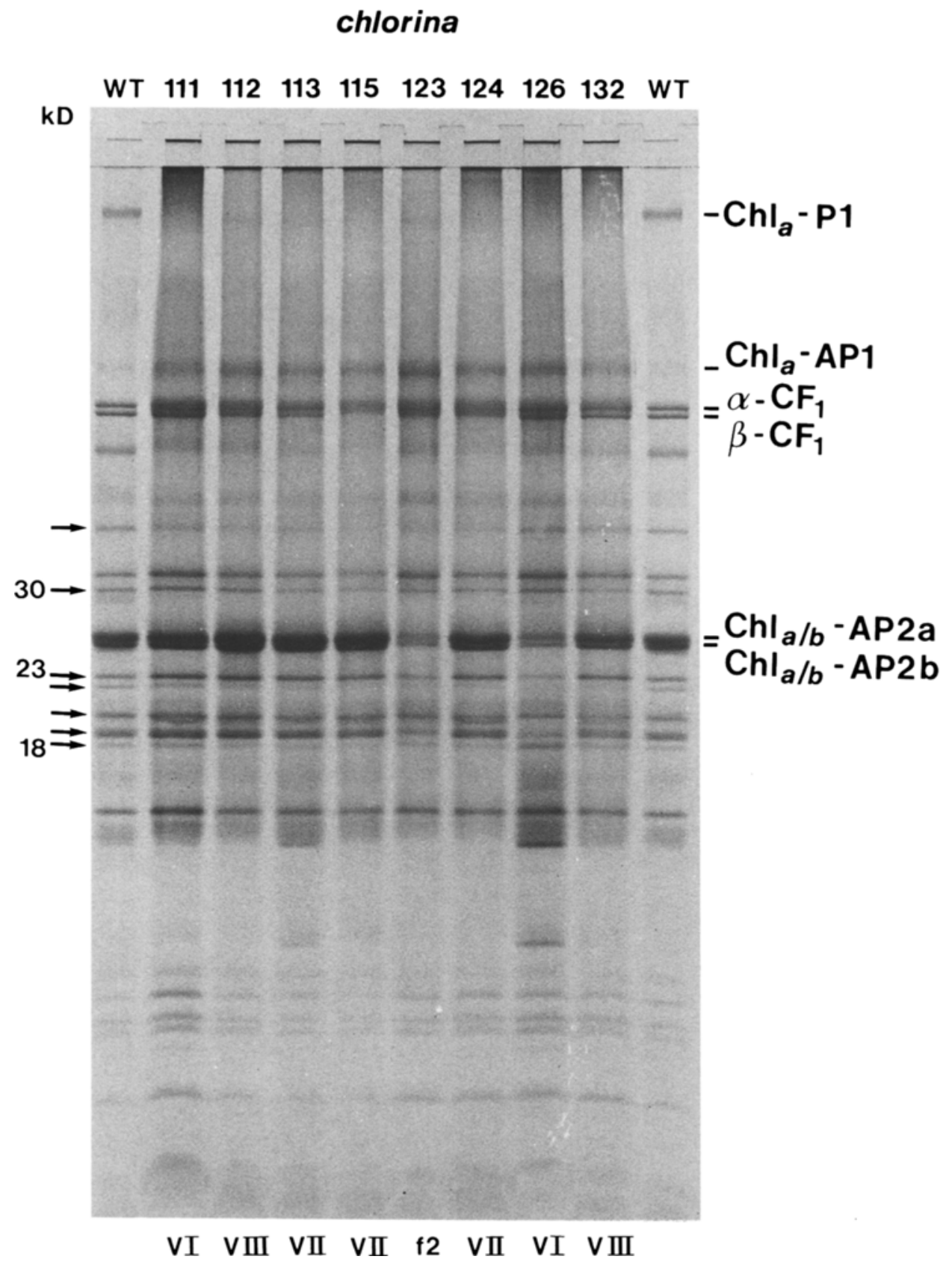

spectroscopy were approximately double the actual values determined by HPLC, all being between 3.7 and 4.4 (Table VI). There was a small increase in the $t_{1 / 2}$ values, indicating a PSII unit size smaller than wild-type, but not as small as those of non-leaky mutants in the chlorina- $f 2$ gene. An interesting feature of these mutants was a high Fm/Fo ratio compared with wild-type (Table VI). This ratio is directly proportional to the efficiency of energy transfer from PSII antennae to PSII reaction centres $(4,5)$. A decrease in the amount of Coomassie staining bands after 
D.J. Simpson et al.: Barley chlorina mutants

chlorina

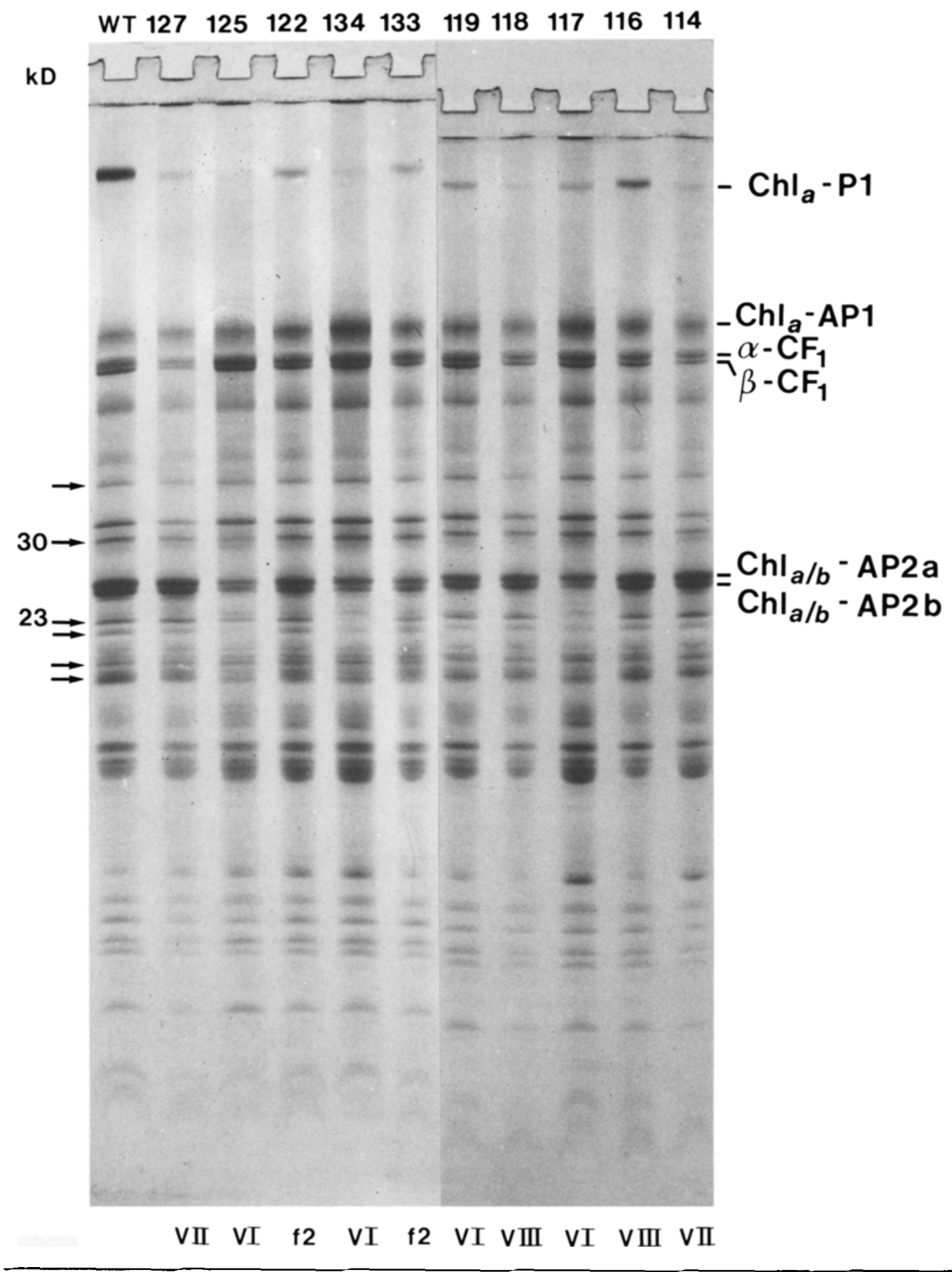


Table VI.

Chlorina mutants with high $\mathrm{F} 680 / \mathrm{F742}$ and $\mathrm{Fm} / \mathrm{Fo}$ ratios

\begin{tabular}{llllllll}
\hline Mutant & $\begin{array}{l}\text { chlorophyll } \\
\text { (\% of WT) }\end{array}$ & $\begin{array}{l}\text { chlorophyll } \\
a / b \text { ratio }\end{array}$ & $\mathrm{t}_{1 / 2}$ & Fm/Fo & Fs/Fo & $\begin{array}{l}77 \text { K fluores- } \\
\text { cence peak }(\mathrm{nm})\end{array}$ & $\begin{array}{l}\text { F685/F742 } \\
\text { ratio }\end{array}$ \\
\hline $104^{*}$ & 67 & 4.46 & 2.42 & 8.216 & 1.269 & 742 & 0.655 \\
$111^{*}$ & 80 & 3.85 & 2.64 & 7.053 & 1.526 & 742 & 0.502 \\
117 & 43 & 4.12 & 5.90 & 7.079 & 2.029 & 737 & 0.531 \\
$119^{+}$ & 67 & 4.36 & 2.64 & 6.038 & 2.822 & 741 & 0.583 \\
125 & 45 & 3.70 & 2.35 & 7.763 & 2.178 & 740 & 0.833 \\
126 & 51 & 4.17 & 3.11 & 6.767 & 2.364 & 737 & 0.578 \\
$129^{*}$ & 44 & - & 4.43 & 7.560 & 1.769 & 742 & 0.403 \\
$130^{*}$ & 78 & - & 2.47 & 6.358 & 2.522 & 739 & 0.401 \\
134 & 53 & 4.40 & 4.61 & 8.255 & 1.932 & 741 & 0.760 \\
wild-type & 100 & 3.38 & 2.16 & 5.898 & 3.064 & 742 & 0.315 \\
\hline
\end{tabular}

*phenotype expressed only under glasshouse growth conditions phenotype expressed only in growth chamber

SDS-PAGE corresponding to $\mathrm{Chl}_{a / b}-\mathrm{P} 2$ and the 20-25 $\mathrm{kD}$ region was also observed (Figure 3 ) for some of these mutants.

Fluorescence induction kinetics could also be used to identify a third class of mutants. These are shown in Table VII and were characterised by an $\mathrm{Fs} /$ Fo ratio $<1$, and a photosynthetic unit size, as determined by $t_{1 / 2}$ values, which was larger than wild-type. An unusual feature of the polypeptide composition of these mutants as a class, was a partial loss of the $\alpha$ and $\beta$ subunits of coupling factor $\left(\mathrm{CF}_{1}\right)$ (Figure 3 ). The amount of the polypeptides corresponding to $\mathrm{Chl}_{a / b}-\mathrm{P} 2$ appeared normal, consistent with their chlorophyll $a / b$ ratios (Table VII), which were close to that of wild-type.
The remaining mutants (Table VIII) closely resembled wild-type in their characteristics, except for a consistently lower chlorophyll content on a fresh weight basis.

\section{DISCUSSION}

Chlorina mutants are viable and differ from the wild-type in the intensity or colour quality of their green pigmentation. Such mutants arise as the result of the accumulation of less chlorophyll on a leaf area basis, the failure to synthesise normal levels of chlorophyll $b$, or the loss of a specific chlorophyll $a / b$-protein. Partial loss of chlorophyll $a$-containing reaction centre proteins can also result in chlorophyll deficiency,

Table VII.

Chlorina mutants with Fs/Fo $<1$

\begin{tabular}{lcllllll}
\hline Mutant & $\begin{array}{l}\text { chlorophyll } \\
(\% \text { of WT) }\end{array}$ & $\begin{array}{l}\text { chlorophyll } \\
a / b \text { ratio }\end{array}$ & $\mathrm{t}_{1 / 2}$ & Fm/Fo & Fs/Fo & $\begin{array}{l}77 \text { K fluores- } \\
\text { cence peak (nm) }\end{array}$ & $\begin{array}{l}\text { F685/F742 } \\
\text { ratio }\end{array}$ \\
\hline 113 & 56 & 2.93 & 1.33 & 3.102 & 0.795 & 741 & 0.266 \\
114 & 68 & 3.37 & 1.35 & 3.174 & 0.778 & 740 & 0.230 \\
115 & 82 & 3.08 & 1.67 & 2.564 & 0.660 & 741 & 0.215 \\
121 & 49 & 3.69 & 1.31 & 3.415 & 0.880 & 742 & 0.307 \\
124 & 93 & 3.06 & 1.33 & 4.061 & 1.102 & 740 & 0.196 \\
127 & 72 & 3.77 & 1.90 & 3.204 & 0.732 & 740 & 0.192 \\
wild-type & 100 & 3.38 & 2.16 & 5.898 & 3.064 & 742 & 0.315 \\
\hline
\end{tabular}


Table VIII.

Chlorina mutants with wild-type characteristics

\begin{tabular}{lcllllll}
\hline Mutant & $\begin{array}{l}\text { chlorophyll } \\
\text { (\% of WT) }\end{array}$ & $\begin{array}{l}\text { chlorophyll } \\
a / b \text { ratio }\end{array}$ & $\mathrm{t}_{1 / 2}$ & Fm/Fo & Fs/Fo & $\begin{array}{l}77 \text { K fluores- } \\
\text { cence peak (nm) }\end{array}$ & $\begin{array}{l}\text { F685/F742 } \\
\text { ratio }\end{array}$ \\
\hline 110 & 77 & 3.33 & 1.73 & 6.026 & 2.617 & 742 & 0.219 \\
112 & 73 & 3.00 & 2.05 & 5.092 & 1.944 & 742 & 0.219 \\
116 & 77 & 3.67 & 1.80 & 5.514 & 3.229 & 742 & 0.326 \\
118 & 75 & 3.76 & 1.86 & 4.872 & 1.331 & 742 & 0.391 \\
132 & 61 & 3.19 & 1.73 & 5.972 & 1.958 & 742 & 0.302 \\
wild-type & 100 & 3.38 & 2.16 & 5.898 & 3.064 & 742 & 0.315 \\
\hline
\end{tabular}

but such plants would be expected to grow poorly, if at all, in the field. The most interesting mutants would be those lacking individual chlorophyll $a / b$-proteins, four of which have been isolated and partially characterised to date (2, $11,13)$.

$77 \mathrm{~K}$ fluorescence emission spectroscopy would seem to be a most promising screening technique. It provides information directly about the chlorophyll-proteins in the thylakoids, particularly after analysis by Gaussian deconvolution, and a small amount of leaf material is sufficient. This technique has been used for barley (16), algae (14, 17) and Porella (17). The spectrum from thylakoids isolated from wildtype barley was composed of 7 peaks with maxima at $680,686,696,708,731,740$ and 761 $\mathrm{nm}(16)$. The present work obtained a similar result with whole leaves except that the 708 and $731 \mathrm{~nm}$ components were replaced by a single Gaussian at $715 \mathrm{~nm}$ and an extra component at $770 \mathrm{~nm}$ was also required. It should be noted that these spectra were not corrected for reabsorption which is particularly important at shorter wavelengths. This can affect both the amplitudes and peak wavelengths of the Gaussians (27). Furthermore, the curve fitting programme does not produce a unique solution and depends on the initial estimates for the curve parameters.

The small amplitude $680 \mathrm{~nm}$ band in wildtype, which is missing from the chlorophyll $b$-less mutants, has been associated with the presence of $\mathrm{Ch}_{a / b}-\mathrm{P} 2$ and is a significant component only below $77 \mathrm{~K}$ (18). Peaks at 685 and 694 $\mathrm{nm}$ may arise solely from chlorophyll $a$ in the PSII reaction centre (14), but a $\mathrm{Chl}_{a / b}-\mathrm{P} 2$ contribution cannot be excluded. Investigations on isolated PSI preparations $(2,15)$ indicate that the 715-720 nm component comes from chlorophyll $a$ antenna close to $P-700$, and that the 737-742 $\mathrm{nm}$ component arises from chlorophyll less tightly coupled to the reaction centre (LHCI730). The origin of the $761 \mathrm{~nm}$ and $770 \mathrm{~nm}$ components is not known.

Some predictions can be made about the properties expected for gene mutants lacking individual chlorophyll $a / b$-proteins from the model for PSI energy transfer (2). Mutants lacking only $\mathrm{Chl}_{a / b}-\mathrm{P} 2$ are expected to have a high chlorophyll $a / b$ ratio $(\approx 10)$, a high $t_{1 / 2}$ value due to a small PSII antenna size, and a 77 K fluorescence emission spectrum characterised by a low yield at 685 and $695 \mathrm{~nm}$ with a normal long wavelength peak at $742 \mathrm{~nm}$ in vivo. The properties of a mutant lacking $\mathrm{Ch}_{a / b}-\mathrm{Pl}$ are difficult to predict since its function is not known. If it serves as a connecting antenna to PSII, analogously to the PSI LHCI-680 (2), such a mutant should have a nearly normal chlorophyll $a / b$ ratio, a high $t_{1 / 2}$ value, and a very high fluorescence yield at $680 \mathrm{~nm}$.

A mutation leading to the absence of the polypeptides comprising LHCI-730 of PSI should have a chlorophyll $a / b$ ratio slightly higher than wild-type, a normal $t_{1 / 2}$ value and an increased yield of $77 \mathrm{~K}$ fluorescence at $720 \mathrm{~nm}$ from the antenna chlorophyll of $P-700 \mathrm{Chl}_{a}-\mathrm{P} 1$. A mutant lacking only LHCI-680 would be the same, except for the $77 \mathrm{~K}$ fluoresence emission spectrum, which should have high yields at 685 , 720 and possibly $732 \mathrm{~nm}$. These predictions are based on the model for exciton transfer in PSI of BASSI et al. (2).

A rather high proportion of the chlorina mu- 
tants were allelic to the chlorophyll $b$-less mutant chlorina- 2 . Of these, only 2 were free of chlorophyll $b$, while 3 were slightly leaky and 5 were very leaky, as determined by HPLC and SDS-PAGE. These mutants all had similar $77 \mathrm{~K}$ fluorescence emission spectra, featuring low yields at 685 and $695 \mathrm{~nm}$, with a broad long wavelength peak blue-shifted up to $7 \mathrm{~nm}$. In isolated chlorina- $f 2$ thylakoids, the long wavelength peak is at $724-727 \mathrm{~nm}(15,21)$ and the amplitudes of the 685 and $695 \mathrm{~nm}$ peaks are much higher. The difference between the in situ and in vitro spectra is largely due to reabsorption of fluorescence at lower wavelengths in the leaf, although this cannot cause the shift from 742 to $724 \mathrm{~nm}$. A value as low as $726 \mathrm{~nm}$ was found for chlorina mutants growing in the glasshouse, due to the increased amplitude of the $720 \mathrm{~nm}$ component relative to that at $737-742 \mathrm{~nm}$. It seems possible that the $720 \mathrm{~nm}$ component is normally quenched by the $737-742 \mathrm{~nm}$ emitting species, but in these chlorina mutants, growth conditions or the age of the leaf, and thylakoid isolation can affect the coupling between the two pigment beds. The origin of the 737-742 $\mathrm{nm}$ fluorescence in chlorophyll $b$-less barley mutants is not known, since they lack the chlorophyll $b$-containing LHCI-730.

The loss of chlorophyll $b$ could be correlated with a proportional decrease in the amount of the chlorophyll $a / b$-proteins of both photosystems, as seen by SDS-PAGE, and an increase in $t_{1 / 2}$ values as the PSII antenna size decreased due to loss of $\mathrm{Chl}_{a / b}-\mathrm{P} 2$. The exception was chlorina 109 , which had a nearly normal $t_{1 / 2}$ value, measured from 4 different leaves. The method used is not exact, being designed for rapid screening for $\mathrm{Chl}_{a / b}-\mathrm{P} 2$ mutants, and should be confirmed using isolated thylakoids.

Only one mutant, chlorina 106, had a high chlorophyll $a / b$ ratio and was not allelic to chlorina- $f 2$. Further characterisation is necessary to establish the nature of this mutation.

The unusual $77 \mathrm{~K}$ fluorescence emission spectra of a second group of mutants (Table VI) were due to increased amplitudes of components at 694 and $718 \mathrm{~nm}$, causing an increased yield at shorter wavelengths and a broader long wavelength peak. These changes are similar to that predicted for a mutant lacking $\mathrm{LHCI}-680$, the
PSI light-harvesting connecting antenna (2). The energy transferred from $\mathrm{Chl}_{a / b}-\mathrm{P} 2$ to PSI is no longer quenched and is emitted as fluorescence at 680 and $695 \mathrm{~nm}$ while the antenna chlorophyll close to $P-700$ cannot transfer energy to $\mathrm{LHCI}-730$ via $\mathrm{LHCl}-680$, causing an increase in $720 \mathrm{~nm}$ fluorescence. Consistent with this, is the loss of polypeptides in the 20-25 $\mathrm{kD}$ region, (Figure 3 ) which corresponds to the known molecular weight of the apoproteins of LHCI-680 $(2,15)$. However, these mutants are also affected to a lesser degree in the amount of $\mathrm{Chl}_{a / b}-\mathrm{P2}$, as seen from the gels (Figure 3) and their $t_{1 / 2}$ values, which are greater than wild-type. It is thus unlikely that any of these mutants are affected in the structural gene(s) for the polypeptides constituting LHCI-680.

The unusually high Fm/Fo ratios from room temperature fluorescence induction kinetics are possibly related to the characteristics of the $77 \mathrm{~K}$ fluorescence emission spectra. BUTLER $(4,5)$ has suggested that a high Fm/Fo ratio may be characteristic of interconnected PSII units able to transfer energy among themselves, but not to PSI ( $\alpha$ centres), and a low Fm/Fo ratio is expected for PSII $\beta$ centres, which can transfer energy to PSI but not to other PSII units. If PSII $\beta$ units were absent, or present but unable to transfer energy to PSI units due to the absence of LHCI-680, then the Fm/Fo ratio of whole thylakoids should increase.

It is relevant that two other mutants of barley, viridis- $s^{44}(25)$ and xantha- $k^{83}$ (SIMPSON, unpublished data) are characterised by high Fm/Fo ratios and $77 \mathrm{~K}$ fluorescence emission spectra similar to these chlorina mutants. Both mutants accumulate $\mathrm{Mg}$-protoporphyrins and/or protoporphyrin when fed $\delta$-amino levulinic acid in the dark (8, SIMPSON, unpublished data), which are possible feedback inhibitors of the accumulation of $\mathrm{Chl}_{a / b}-\mathrm{P} 2$ mRNA (10). By inference, they may be effective inhibitors of LHCI-680 mRNA accumulation.

The mutants having a Fs/Fo ratio $<1$ (Table VII) have a chlorophyll $a / b$ ratio close to, or slightly below wild-type, with normal levels of $\mathrm{Ch}_{a / b}-\mathrm{P} 2$. They also have low $\mathrm{t}_{1 / 2}$ values indicating a larger than normal PSII unit size and a low Fm/Fo ratio. These properties are typical of thylakoids partially deficient in PSII reaction 
centres, but having a normal $\mathrm{Ch}_{\alpha / b}-\mathrm{P} 2$ content, such as viridis- $m^{29}(23)$ and manganese-deficient barley or spinach (24). It is not possible to discern any differences in the polypeptide pattern (Figure 3 ) in the region where the apoproteins of $\mathrm{Chl}_{a}-\mathrm{P} 2$ and $-\mathrm{P} 3$ run, but it is probable that the differences are small since these mutants grow quite well in the field. The decreased amount of $\mathrm{CF}_{1}$ seems unlikely to be directly responsible for the observed properties of this class of chlorina mutants. Measurement of PSIIdependent electron transport reactions and freeze-fracture ultrastructure should aid in the determination of the precise nature of the lesion in these chlorina mutants.

\section{ACKNOWLEDGEMENTS}

The authors are grateful to Dr. SIMON GougH for stimulating discussions and assistance with the HPLC. The programme RESOL was made available by the generosity of Dr. J. BROWN of the Carnegie Institute. The first ten chlorina mutants were selected in 1979 with the assistance of Dr. B.L. MøLLER. We wish to thank KIRSTEN KRISTIANSEN and BENTE JENSEN for excellent technical assistance, and NINA RASMUSSEN and ANN-SOFI STEINHOLTZ for preparing the figures.

\section{REFERENCES}

1. APEL, K. \& K. KLopPSTeCH: The plastid membranes of barley (Hordeum vulgare). Light-induced appearance of mRNA coding for the apoprotein of the light-harvesting chlorophyll $\mathrm{a} / \mathrm{b}$ protein. Eur. J. Biochem. 85, 581-588 (1978)

2. BASSI, 'R., O. MACHOLd \& D. SimPSON: Chlorophyll-proteins of two photosystem I preparations from maize. Carlsberg Res. Commun. 50, 145-162 (1985)

3. Boardman, N. K. \& S. W. Thorne: Studies on a mutant lacking chlorophyll b II. Fluorescence properties of isolated chloroplasts. Biochim. Biophys. Acta 448-458 (1968)

4. ButLer, W. L.: Exciton transfer out of open photosystem II reaction centers. Photochem. Photobiol. 40, 513-518 (1984)

5. Butler, W. L., D. Magde \& S. J. Berens: Fluorescence lifetimes in the bipartite model of the photosynthetic apparatus with $\alpha, \beta$ heterogeneity in photosystem II. Proc. Natl. Acad. Sci., USA 80, $7510-7514$ (1983)

6. Canaani, O. D. \& K. Sauer: Absorption and circular dichroism spectra of chloroplast membrane fragments from spinach, barley and a barley mutant at room temperature and liquid nitrogen temperature. Biochim. Biophys. Acta 501, 544551 (1978)

7. Casadoro, G., G. Høyer-Hansen, C. G. KanNANGARA \& S. P. Gough: An analysis of temperature and light sensitivity in tigrina mutants of barley. Carlsberg Res. Commun. 48, 95-129(1983)

8. Henningsen, K. W. \& B. StummanN: Use of mutants in the study of chloroplast biogenesis. In: Encyclopedia of Plant Physiology (B. Parthier \& D. Boulter eds. ) Springer Verlag, Berlin. Vol. 14B, 598-644 (1982)

9. JENDE-STRID, B.: Mutation frequencies obtained after sodium azide treatment in different barley varieties. Barley Genet. Newsl. 8, 55-57 (1978)

10. JOHANNINGMEIER, U.\&S. H.HowELL: Regulation of light-harvesting chlorophyll-binding protein mRNA accumulation in Chlamydomonas reinhardi. J. Biol. Chem. 259, 13541-13549 (1984)

11. Machold, O. \& A. Meister: Resolution of the light harvesting chlorophyll-a/b protein of Vicia faba chloroplasts into two different chlorophyllprotein complexes. Biochim. Biophys. Acta 546, 472-480 (1978)

12. Machold, O., A. Meister, H. Sagromsky, G. Høyer-Hansen \& D. von WetTstein: Composition of photosynthetic membranes of wild-type barley and chlorophyll $b$-less mutants. Photosynthetica 11, 200-206 (1977)

13. Machold, O., D. J. Simpson \& B. L. Møller: Chlorophyll-proteins of thylakoids from wild-type and mutants of barley (Hordeum vulgare L. ). Carlsberg Res. Commun. 44, 235-254 (1979)

14. Moya, I. \& R. Garcia: Phase fluorimetric lifetime spectra I. In algal cells at $77 \mathrm{~K}$. Biochim. Biophys. Acta 722, 480-491 (1983)

15. Mullet, J. E., J. J. Burke \& C. J. Arntzen: A developmental study of photosystem I peripheral chlorophyll proteins. Plant Physiol. 65, 823-827 (1980)

16. Nielsen, N.C., R. M. Smillie, K. W. Henningsen, D. von WETTSTEIN \& C. S. FReNCH: Composition and function of thylakoid membranes from granarich and grana-deficient chloroplasts of barley. Plant Physiol. 63, 174-182 (1979)

17. ÖQUisT, G. \& D. C. ForK: Effects of desiccation on the excitation energy distribution in the red alga Porphyra perforata, the liverwort Porella navicularis, and the isolated lichen green alga Trebouxia pyriformis. Carnegie Inst. Year Book 80, 34-38 
(1980)

18. RiJgersberg, C.P., J. AMesz, A. P.G. M. THIELEN \& J. A. SWAGER: Fluorescence emission spectra of chloroplasts and subchloroplast preparations at low temperature. Biochim. Biophys. Acta 545, 473-482 (1979)

19. SAGROMSKY H.: Zur physiologischen Bedeutung von Chlorophyll b. Biochem. Physiol. Pflanzen. 166, 95-104 (1974)

20. Schmidt, G. W., S. G. Bartlett, A. R. Grossman, A. R. CASHMORE \& N. -H. Chua: Biosynthetic pathways of two polypeptide subunits of the light-harvesting chlorophyll $\mathrm{a} / \mathrm{b}$ protein complex. J. Cell Biol. 91, 468-478 (1981)

21. Searle, G. F. W., C. J. Tredwell, J. Barber \& G. PORTER: Picosecond time-resolved fluorescence study of chlorophyll organisation and excitation energy distribution in chloroplasts from wild-type barley and a mutant lacking chlorophyll b. Biochim. Biophys. Acta 545, 496-507 (1979)

22. Simpson, D. J.: Freeze-fracture studies on barley plastid membranes III. Location of the light-harvesting chlorophyll-protein. Carlsberg Res. Com- mun. 44, 305-336 (1979)

23. SimpSON, D. J.: The ultrastructure of barley thylakoid membranes. In: Photosynthesis III. Structure and Molecular Organisation of the Photosynthetic Apparatus (G. Akoyunoglou ed.) Balaban Int. Sci. Services, Philadelphia, Pa. pp. 15-22 (1981)

24. SIMPSON, D. J. \& S. P. RoBinSON: Freeze-fracture ultrastructure of thylakoid membranes in chloroplasts from manganese-deficient plants. Plant Physiol. 74, 735-741 (1984)

25. Simpson, D. J. \& D. von WetTSTEIn: Macromolecular physiology of plastids XIV. Viridis mutants in barley: genetic, fluoroscopic and ultrastructural characterisation. Carisberg Res. Commun. 45, 283-314 (1980)

26. THORNBER, J. P. \& H. R. HighKIN: Composition of the photosynthetic apparatus of normal barley leaves and a mutant lacking chlorophyll b. Eur. J. Biochem. 41, 109-116 (1974)

27. WEIS, E.: Chlorophyll fluorescence at $77 \mathrm{~K}$ in intact leaves: Characterization of a technique to eliminate artifacts related to self-absorption. Photosyn. Res. 6, 73-86 (1985)

Accepted by S. O. ANDERSEN 